\title{
Ugh
}

\section{Sladjana Courson}

Ugh. I am ashamed to say that is the first word that comes to my mind when I see Jake's name on my schedule for the day. He is 10 and he has been my patient since he was born. He has an 8-year-old sister Annie and a 5-year-old brother Jimmy. They usually all come in together with their mother even if only one of them has an appointment that day. They all have a variety of mental health diagnoses, including ADHD, OCD, and PTSD, and Jake also has autism. It has not been easy to align him with mental health providers. I have tried to help mom deal with his aggressive behaviors - the hitting, biting, and yelling-but I feel that I have failed them on several occasions. Mom tries her best, but she has some cognitive delays herself and doesn't always know how to handle him. Regularly they are in the emergency room where he is given medications to sedate him, and then they are then sent home. They come to their appointment with me and I feel helpless. How do I get this family all the assistance and guidance they need?

\footnotetext{
S. Courson $(\bowtie)$

Akron Children's Hospital, Akron, OH, USA

Northeast Ohio Medical University, Rootstown, OH, USA

e-mail: scourson@akronchildrens.org
} 